\title{
Family Environment, Sibling Relationship and Rivalry towards Quality of Life
}

\author{
Rugayah Hashim ${ }^{1 *}$, Hashim Ahmad ${ }^{2}$ \\ 1,2 Faculty of Administrative Science \& Policy Studies, Universiti Teknologi MARA, 40450 Shah Alam, Selangor, Malaysia
}

\begin{abstract}
Kinship, family composition and household dynamics among siblings are developed positively or negatively in early life right through adulthood. Hence, the purpose of this paper is highlight the importance of family environment in influencing sibling relationship, with emphasis on sibling rivalry. Determining the factors that contribute towards sibling competition is important in counselling and assisting individuals with family issues. From a quantitative research approach, the findings showed that sibling relationships are problematic and has led to jealousies and prejudices especially if parents take sides. Family ties depend on happy sibling interactions which indirectly affects socio-economic developments as social ills are resolved. In ameliorating these private and sensitive issues among family members, the holistic society will benefit psychologically and happiness as well as a better quality of life will be attained.
\end{abstract}

(C) 2016. The Authors. Published for AMER ABRA by e-International Publishing House, Ltd., UK. This is an open access article under the CC BY-NC-ND license (http://creativecommons.org/licenses/by-nc-nd/4.0/).

Peer-review under responsibility of AMER (Association of Malaysian Environment-Behaviour Researchers), ABRA (Association of Behavioural Researchers on Asians) and cE-Bs (Centre for Environment-Behaviour Studies), Faculty of Architecture, Planning \& Surveying, Universiti Teknologi MARA, Malaysia.

Keywords: Sibling rivalry; family; quality of life; socio-economic impact

\section{Introduction}

Family ties are important in all communities. The relationship among members of a family is highly dependent on human factors, in particular, the leadership abilities of both the father and mother. From here, the kinship, family composition and household dynamics among siblings are developed positively or negatively in early life right through adulthood. Nonetheless, quarrels and differences among siblings is a normal occurrence among families. However, the intensity and gravity of the rivalry depends on the situation. For example, in Malaysia, the occurrence of sibling

\footnotetext{
* Corresponding author. Tel.: +60355444158

E-mail address: gy@salam.uitm.edu.my
}

2398-4287 @ 2016. The Authors. Published for AMER ABRA by e-International Publishing House, Ltd., UK. This is an open access article under the CC BY-NC-ND license (http://creativecommons.org/licenses/by-nc-nd/4.0/).

Peer-review under responsibility of AMER (Association of Malaysian Environment-Behaviour Researchers), ABRA (Association of Behavioural Researchers on Asians) and cE-Bs (Centre for Environment-Behaviour Studies), Faculty of Architecture, Planning \& Surveying, Universiti Teknologi MARA, Malaysia.

DOI: http://dx.doi.org/10.21834/e-bpj.v1i3.356 
rivalries leading to fights and fatalities have increased over the past decade. Such incidences have been highlighted by the media. Hence, the purpose of this paper is to focus on the importance of family environment relative to sibling relationship with emphasis on sibling rivalry. Again, the motivation of the study was prompted by the many cases of sibling rivalries that has resulted in fatalities in Malaysia. Determining the factors that contribute towards sibling competition is important in counselling and assisting individuals with family issues. As this is a fundamental study, theoretical implications are grounded towards the identification of these factors.

\section{Background}

Sibling relationship especially sibling rivalry has received scarce attention unlike child abuse and neglect. As pointed out by Whiteman, McHale and Soli (2011), siblings are a fixture of family life. In families with more than one child, siblings at odds are considered normal (Blake, 1981; Donovich, Puschmann, \& Matthijs, 2014; Fawcett et al., 1974). With increasing incidences of sibling fights, this area of research should be the focus of universities to highlight the plights to the relevant authorities. In stimulating the interest in sibling relationship or 'sibship', theoretical perspectives should be undertaken as a guide for future investigations by scholars in family sociology.

Anyhow, sibling relationships are exclusive as this trait is often associated with its durability among siblings. This has been supported by the fact that this relationship is one of the longest relationships in one's life as sibling share common culture, understanding and family members. The interaction and situation among siblings will be highly determined on their perception about this relationship. However, despite its durability, we can still see that one sibling relationship is warm and harmony while others might experience conflict and misunderstanding. Hence, this situation reflects that sibling relationship is not totally dominated on the siblings themselves but might be influenced by other people, surroundings and obstacle faced. Even within the same family, one person might be comfortable or favours to one sibling than another (Wallace, 2012).

With that explanation, this paper is indeed a fundamental study with little psychologically-oriented perspectives as the authors are not qualified psychologist. Suffice is to say, the social learning and family-ecological systems formed the theoretical underpinnings of this research project.

\section{Problem Statement}

In Southeast Asia, most families consist of more than one child. With culture and religion at play, most families have an average of three children (Blake, 1981; Oshima, 1962). Weakness or problems in sibling relationship can lead to stumble situation of a family which will indirectly impaired the country's development. Strengthening positive sibling relationship is an ultimate measure to endorse healthy family functioning, cultivating good psychological health and social competence and preventing health risk behavior such as violence in sibling rivalry (Feinberg et al., 2013). Despite the focus on importance of good management on sibling rivalry, limited study has been conducted on this area and the relationship of sibling rivalry towards development of poor personality in the future (Mackey et al., 2010).

Moreover, as shown by Yucel and Yuan (2015), the number of siblings in a family affect their socio-emotional development and educational aspirations but only at the early adolescent stage. At early adulthood and past last adulthood, sibling rivalry increases resulting in serious altercations including fatalities. Therefore, this study comes at an appropriate time where sibling fights in Malaysia is on the increase as reported in the media. The seriousness of the situation requires immediate mediation by the relevant authorities to curb further aggravation among family members and this in turn, will affect the quality of life and the community.

\section{Research Questions and Objectives}

With regards to the problem statement, the research questions for this study are:

i) What are the factors that contribute towards sibling rivalry in Malaysia?

ii) Does family size influence sibling rivalry?

Based on the above research questions, the research objectives undertaken for this project are: 
i) To determine the factors that contribute towards sibling rivalry in Malaysia, and

ii) To evaluate the influence of family size on sibling rivalry. Significance of Study

This study is significant at the findings will have bearings on family life, values and happiness in Malaysia. When one family is a happy one, the communities and other socio-economic factors will be positively impacted. As detailed in the background of the study, incidences of siblings at odds were hardly reported until now when the seriousness of the matter was brought to prominence by the media, namely the newspapers. With the changing of times and in the Information Era, family feuds among conservative Asian communities should not be kept in the dark. Help you be at hand through agencies and trained individuals so that the family's well-being and quality of life is attained. In particular, the Ministry of Women, Family and Community Development, Malaysia would gain adequate information on how to handle this aspect of family issues that is considered sensitive and private.

\section{Literature Review}

\section{Sibling Relationship}

Whether brothers or sisters, the interaction between siblings is important for family harmony. As we know, siblings are people who are under the purview of the same parents, yet each of them are their own individuals with unique characteristics and emotional needs. Thus, parents play vital roles in ensuring the individual's need of each child is properly attended. The first step played by parents is important as this measure could prevent sibling rivalry being cultivated at the early age. Sibling abuse or sibling rivalry can be described by the jealousy, competition and fighting between brothers and sisters. Problems often start right after the birth of the second child that usually continues throughout childhood. Sibling rivalry is a common term used in the culture. However, the definition and the concept understanding are more complicated than we thought. Historically, sibling rivalry has been defined primarily in terms of birth order and competition. This issue has been originating from the grudge of an older sibling toward a younger sibling for stealing parental affection. Together with sibling abuse, negative progression outcome may be companion with sibling rivalry. The most extensive obstacle with sibling rivalry is the chances of an impaired sibling relationship (Mackey, Ellen, \& Kelly, 2010).

International Classification of Disease (ICD-10), has stated that sibling rivalry is a disorder that distinctive by evidence of jealousy; onset during the months following the birth of the younger sibling and development of persistent emotional disturbance (Barrow, Heyman, Scott, \& Krebs, 2014). Rivalry became into violence when the identities aggressor and the loser are clearly seen, as it is set towards leaving the victimised sibling humiliated, defeated and unprotected. If sibling rivalry is left unattended, it will slowly progress into a form of unintended behaviour, violence. The common type of this violence is called domestic violence such as child abuse, elderly abuse and women abuse. Nevertheless, sibling violence is still underreporting even though most of the researchers believe that this kind of violence is customary occurred. (Inês Carvalho Relva Otilia Monteiro Fernandes Catarina Pinheiro Mota, 2013). Sibling violence is often seen as a normal process of rivalry and thus it is difficult to recognise. Most of the combative interaction between siblings is frequently accepted as a normal dispute. It has also rarely viewed as criminal. Most of the victim do not realise that this type of action is a kind of violence (Tucker, Finkelhor, Shattuck, \& Turner, 2013).

The seriousness of the sibling rivalry or sibling abuse can be identified when it has transformed into violence. The violence can be appeared in the form of physical, psychological, sexual, economic, social, spiritual (Siti Hawa Ali, 2002). Nevertheless, most of the frequent reported cases are the physical, emotional and sexual abuse. Physical abuse can be in many forms of physical contact such as pushing, slapping, kicking, biting, and beating. The aggressor could be using an object like a knife, a belt, a stick or any other threatening object. The abuse can also be collective, when several siblings unite against the victim, and are mostly accompanied by emotional violence. Emotional aggression, sometimes-referred to as psychological aggression, includes name offensive impression, taunting, and threatening another sibling. The aggressor's main objective is devaluating the other sibling 
and showing off his power and control (Tucker et al., 2013). After all, we still can see that in the real world, siblings violence or siblings abuse is still underreported (Inês Carvalho Relva Otília Monteiro Fernandes Catarina Pinheiro Mota, 2013).

Embarking on a strategy to ensure sustainable approach and outcome in resolving sibling rivalry and sibling abuse cases will direct us to future-proofing solution. This conflict is about finding the gaps and underlying contributing factors of issue in the systems, processes involved and solutions available so we can create a vital long-term impact solution. Combining science with our tradition knowledge will lead to a holistic approach to initiate prevention of this problem. Sibling rivalry is a condition exists due to the need of the children to overcome their inferiority feelings. This inferiority feeling is often caused by the competition among siblings. The competition to gain parental attention and rewards has caused rivalry among each other. One of the parental approaches suggested in order to eliminate the inferiority among our children is through the implementation of dis-identification among children. The family tradition or custom in terms of favouritism or different treatment among children can lead to unhealthy family environment. Thus by implementing dis-identification, the children will not feel that they need to fight for a positive identification such as 'the smartest', 'the artistic' and so on (Ben Kerrane Shona M Bettany Katy Kerrane, 2015).

Stressing that factors influencing sibling rivalry is also a dominant aspect in a transformation agenda especially in the welfare development among citizens. In the qualitative study conducted by Wallace in 2012 has revealed that gender, number of siblings, age and gap between siblings were underling factors that influence sibling rivalry among siblings. Thus, through a committed and supportive research community, identification of problem solving barrier and strategies policy factors that may impact on better sibling rivalry management outcome. The findings will inform policy and together with results, will provide essential information for the design of an appropriate sibling rivalry intervention in Malaysia. In conjunction with this solution, theoretical frameworks for intervention with sibling abuse are needed. This is because limited of on-going study addressing sibling abuse and sibling rivalry is a principle answer that the understanding of this phenomenon is limited worldwide (Meyers, 2015).

This research builds on work that has been initiated internationally and will explore how sibling rivalry and sibling abuse can be greatly reduced and overcome through changes to policy and social factors mechanism. Besides that, it is vital that precise diagnosis is made and suitable management being provided for sibling abuse as this may lead to may lead to future psychological and emotional difficulties for both siblings involved, and other family members (Barrow et al., 2014). Previous research has outlined that the management of sibling rivalry and abuse consist of two stages. The first stage is assessment stage which involve family culture, strength and weakness is being assessed which can help to put the family at ease. While the second stage of sibling rivalry management is intervention stage. In this stage, mutual agreement between family members and conflict resolution strategy being introduced to the family (Kiselica \& Morrill-Richards, 2007). In addition, the better understanding on solution of sibling rivalry issue is crucial as it indicates the direction of future research (Whiteman, 2012).

\section{Sibling Rivalry in Malaysia}

Malaysians have been known for their strong belief to culture and tradition. In the case of sibling rivalry, many of the population regard this as a private matter and should be kept among family members only. The thought that revealing the issue to respective personnel even if the sibling rivalry has been complicated and leads to violence would be considered as an embarrassment for them. The violence reported involving abandonment, neglecting, physical abuse, sexual abuse and emotional abuse (Jabatan Kebajikan Masyarakat, 2007). On top of that, a survey of family conflict revealed that $70 \%$ of families reported physical violence between siblings, and over $40 \%$ of children were kicked, bitten, or punched by their siblings in annually (Feinberg, Sakuma, Hostetler, \& Mchale, 2013)

Sibling rivalry has been an issue that attracts serious attention not only in Malaysia but in the other countries as well. In the well-developed country like Unites States has also been reporting that sibling abuse has been pinpointed as the most common type of family violence (Meyers, 2015). This study, which was conducted by Social Work Department, has been highlighting that the issue of sibling rivalry has been a tremendous areas to tackle with. This finding has been a revelation and has been a remarkable justification for each country to handle, as this issue can no longer be considered as family or internal affairs only. In our country, a cumulative statistics from the year of 2006-2007 has showed that 97 cases of abuse in Malaysia among child has been caused by siblings (Welfare 
Department Malaysia, 2007). Not only that, we can see our neighbouring country, Indonesia has published an article highlighting the sibling rivalry impact among biological and foster sibling (Marazyan, 2011). Increased of acceptance among public in terms of reporting or seek advice on sibling rivalry issue will serve as a precursor towards the development of policy module in overcoming this situation. By identifying risk groups of family that has tendency to develop sibling rivalry among their children, underlying factors contributing to sibling rivalry and sibling abuse risks, interventions can be better targeted by the stakeholders and nation to reduce these affairs. The facts that $40 \%$ of children in the United States engage in physical aggression against siblings, and as many as $85 \%$ engage in verbal aggression against siblings on a regular basis should be an alarming trigger for our Malaysian society (Kiselica \& Morrill-Richards, 2007). Despite this important progress, violence against siblings, is still widely disregarded by the media and professional literature. In addition, data shows that sibling rivalry and sibling abuse is the most prevalent forms of domestic violence compared to the others. This should be taken seriously into consideration as homicide in the United States mention that siblings perpetrated $6.1 \%$ of all murders committed by family members in 2002 . This figure is startling and point out that sibling relationships can be marred by violence (Kiselica \& Morrill-Richards, 2007).

Malaysia has gained terrific momentum in terms of societal stability of the country. Thus, we want to maintain and build on to ensure we can continue to have an impact and achieve our mission of making real positive outcome in solving sibling rivalry issue. The excellent record of society stability has been created through work that aims to reduce domestic violence and bad impact of it such as fatalities (Women's Aid Organisation, 2015). Family institution is a well-known fact and key factors that resemble the success of the nation. Sibling relationship is one of the key elements that contribute towards the formation of a stable and strong family institution. Approaches and implementation done in other country have given us Malaysian ideas on how should we construct our policy changes despite strong belief towards our tradition in the issues involving our family bonding. Proper guideline framework as well as inputs towards policy changes will eventually help to create a safe and positive relationship in the family structure among Malaysians. This measure is important as being supported by previous study which indicate that sibling aggression, however, has been shown to be associated with a number of poor outcomes including lower well-being, negative externalizing behaviors and relationship problems (Tucker et al., 2013). The theoretical model being developed by previous study has been focusing on the key pathway of targeting sibling conflict solution, which later extends their experiences into their surroundings and later adolescent year have given us concrete justification for such measure to be implemented in Malaysian culture (Feinberg et al., 2013).

\section{Methodology}

\section{Type of Research}

The type of research that was used for this study is qualitative research as the aim is to gather in-depth understanding on sibling relationship and rivalry. The discipline investigates the "what" and "why" of the issue at hand. Moreover, from literature reviewed, most of the methodologies attempted for this kind of investigations have focused on secondary data analyses, or library research. This involves identifying and locating sources that provide factual information or personal/expert opinion on a research question as this is a necessary component of every other research method at some point (George, 2008). Therefore, at the initial phase, the research groundwork was conducted using the library research method which forms the theoretical groundwork for this paper. The following sources were used to locate relevant literature about the sibling rivalry and abuse: PubMed, SAGE, EBSCO Host, Science Direct and Emerald Insight. The studies were limited to English language articles and current publication year. Combinations of the following terminologies, "sibling" AND "rivalry" and "sibling" AND "abuse" were used to identify appropriate studies. In addition, mass media reports on the selected terminologies have been selected for the study review. The papers and reports, which fulfilled the terminologies and requirements of the study, have been included. Statistics reported by local authorities were amassed but will not be reported in this paper. Also, a quantitative approach was deemed appropriate in achieving the research objectives. As such, prior to the actual collection of data, a pilot study was conducted among college students at UiTM Shah Alam to determine the existence of this issue and the factors that lead to the altercations. 


\section{Sampling method and respondents}

The research sampling method that was used for the pilot study is non-probability sampling, specifically convenience sampling. Students from a class taught by the researcher volunteered to answer the questionnaire administered. A total of 15 students responded with a rate of $100 \%$. These students were from the Faculty of Administrative Science and Policy Studies, Universiti Teknologi MARA, Shah Alam, Selangor, Malaysia.

\section{Questionnaire}

The questionnaire requires information about the demographics and family background of the respondents. It also has statements related to family and sibling relationships. The statements are perceptions on the occurrence of sibling rivalry and one open-ended question was posed to glean more feedbacks that form the rich information to justify the existence of this issue.

\section{Theoretical Framework}

As previously noted, this research project is a fundamental study where theories play a crucial part in understanding the phenomena. Again, from literature search, the theoretical underpinnings underscore the structure of the investigation. The framework is shown in Figure 1.

The first four theories for sibling relationship (Psychoanalytic-evolutionary, social psychological, family-ecological systems and social learning theories) lean more towards psychological assessments or psychiatry. Only two of the theories are suitable for this study. They are the family-ecological systems and social learning theories. For the sibling rivalry construct, three theories were found from literature which are the attachment theory, individual psychology and ethological theories. Although there are other relevant theories such as the life course (Elder, 1996) and feminist perspectives (Walker, Allen \& Connidis, 2005), these works can be taken up for future fundamental research.

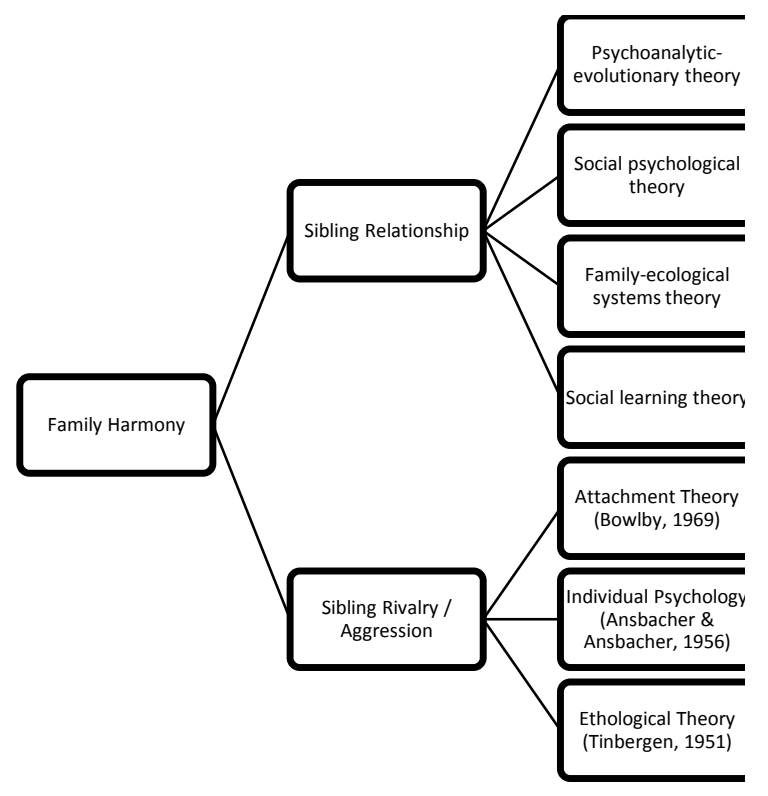

Fig. 1. Theoretical Framework on Sibling Relationship and Rivalry 


\section{Findings}

The analysis of the pilot study from the 15 responses are shown their demographic profiles (Table 1). The average age range of the respondents is $21-25$ years at $80 \%$. All of the students are postgraduates with a gender breakdown of $13.3 \%$ male and $86.7 \%$ female. Full-time students make up $86.7 \%$ of the population and as for birth order, $40 \%$ are second born, $26.7 \%$ are later born (either fifth born and above). The eldest and third child category is at $13.3 \%$.

For sibling relationship (see Table 2), three questions were asked. On whether their parents are treating them and siblings equally, $26.7 \%$ noted that sometimes their parents treat their sibling much better than they. For the second question, the respondents indicated that they long for their sibling's return (53.3\%) should their sibling is temporarily absent from home. For the last question, $33.3 \%$ of respondents showed happiness and jealousy if someone says that his or her sibling is better than they are.

For Table 3 on sibling rivalry, three statements were posed. Nine $(60 \%)$ respondents indicated that they were aware of the clear distinction between a healthy sibling rivalry and sibling aggression. Moving on, the second statement is on the normalcy of sibling rivalry and that parents should not be worried about it. Sixty percent of the respondents agree to that statement and for the last one, $40 \%$ agreed that sibling rivalry disappears when children grow up.

Table 1. Respondents' Profiles

\begin{tabular}{llll}
\hline Item & Detail & Frequency & Percentage \\
\hline Age & $21-25$ years & 12 & 80.0 \\
& $26-30$ years & 2 & 13.3 \\
Education & $31-35$ years & 1 & 6.70 \\
Gender & Master & 15 & 100 \\
& Male & 2 & 13.3 \\
Student Status & Female & 13 & 86.7 \\
& Full time & 13 & 86.7 \\
Birth Order & Part time & 2 & 13.3 \\
& First born & 2 & 13.3 \\
& Second born & 6 & 40.0 \\
& Third born & 2 & 13.3 \\
& Fourth born & 1 & 6.70 \\
\hline
\end{tabular}

Table 2. Sibling Relationship

\begin{tabular}{llll}
\hline Question & Detail & Frequency & Percentage \\
\hline Do you think that your parents & Yes & 11 & 73.3 \\
are treating you and your & No & 0 & 0 \\
sibling(s) equally? & Sometimes they treat my sibling good more than me & 4 & 26.7 \\
& They never care for us & 0 & 0 \\
If your sibling leaves home & Happy & 1 & 6.7 \\
temporarily for something (eg, & Longing for sibling's return & 8 & 53.3 \\
$\begin{array}{l}\text { attending university/work), how } \\
\text { do you feel? }\end{array}$ & Lonely & 6 & 40.0 \\
If someone says that your sibling & Happy & & \\
is better than you, how do you & Jealous & 5 & 33.3 \\
feel? & Feel bad & 5 & 33.3 \\
& Indifferent & 2 & 13.3 \\
\hline
\end{tabular}


Table 3. Sibling Rivalry

\begin{tabular}{|c|c|c|c|}
\hline Statement & Detail & Frequency & Percentage \\
\hline There is a clear distinction & Strongly agree & 3 & 20 \\
\hline between a healthy sibling rivalry & Agree & 9 & 60 \\
\hline and sibling aggression & Not sure & 3 & 20 \\
\hline Sibling rivalry is normal and so & Agree & 9 & 60 \\
\hline parents should not be worried & Not sure & 1 & 6.7 \\
\hline \multirow[t]{2}{*}{ about it } & Disagree & 4 & 26.7 \\
\hline & Strongly disagree & 1 & 6.7 \\
\hline \multirow{5}{*}{ children grow up } & Strongly agree & 1 & 6.7 \\
\hline & Agree & 6 & 40 \\
\hline & Not sure & 3 & 20 \\
\hline & Disagree & 4 & 26.7 \\
\hline & Strongly disagree & 1 & 6.7 \\
\hline
\end{tabular}

\section{Implications and Conclusion}

The findings from showed that sibling relationship and rivalry do exist because of factors such as jealousy and prejudices especially if parents take sides. The responses are evidenced in Table 1 and 2 . Furthermore, the size of the family influences sibling rivalry as shown in Table 1 where $13(86.7 \%)$ of the respondents have more than one sibling. Overall, these results indicated that the Malaysian family environment, sibling relationship and rivalry are influenced by family size. This factor is common for most families in Southeast Asia as culture, tradition and religion form the foundation of communities and society. In fact, most Asian families consist of more than one child, hence, having an average of three children is a normal occurrence. For each family, happiness and bonding are two factors that lead to a sound quality of life and well-beingNonetheless, the impact of the findings will provide policymakers such as the welfare department and the relevant ministries with the information on sibling issues that have not been highlighted because of the conservative nature of the society and the need to avoid embarrassment to the family. In ameliorating these private and sensitive issues among family members, the holistic society will benefit psychologically and happiness as well as a better quality of life will be attained.

Another important implication for this study is the direction for future sibling rivalry research. As posited by Whiteman, McHale, and Soli (2011) is the design of studies that incorporate analyses of a broader range of influence processes. This will illuminate how insights from the various perspectives complement one another. For example, research rooted in psychoanalytic traditions has been important in understanding how dynamics such as parents' differential treatment relate to sibling relationship qualities. (Whiteman et al., 2011). On the other hand,

However, a more complete understanding of these links is possible when other psychological and social processes, such as notions of equity and fairness, as proposed by social psychological theories, and sociocultural forces, as proposed by ecological and systemic perspectives, are taken into account. In this way, research on sibling relationships could serve as a model for studying other kinds of close relationships. Finally, because sibling relationships are the longest-lasting relationship that most individuals share-a quality that makes sibling relationships unique-it is essential that future work examine them over extended periods of time. Longitudinal research on siblings offers family scholars a window into how family relationships develop and change, as well as the opportunity to understand the multiple processes and contexts that influence these lifelong bonds.

In conclusion, this study contributes to highlighting the sibling rivalry and sibling abuse issues do exist in a conservative, Asian families. However, culture, tradition and religion play important roles in hiding incidences of sibling abuse and rivalry for fear of embarrassment to the family. Nonetheless, this research supports the impact of sibling rivalry towards society development, economy stability and nation sustainability. The formation of a policy on sibling rivalry and sibling abuse will serve as evidence based documentation needed by the stakeholders, in particular, for the Ministry of Women, Family and Community Development. The movement towards prevention and intervention of sibling aggression require co-operation not only from the parents but also the whole nation as the presence of sibling rivalry implies uncivil society and ignorance on the seriousness of this issue. 


\section{Acknowledgements}

The researchers would like to acknowledge the funding received towards the conduct of this research project, which is the Fundamental Research Grant Scheme (FRGS 5/3 34/2015) awarded by the Ministry of Higher Education, Malaysia and the support received from the Dean, Faculty of Administrative Science \& Policy Studies, Universiti Teknologi MARA. Lastly, we would like to thank our graduate research assistants, Nur Liyana Zainal Bahrin and Azlan Ahmad from the Faculty of Pharmacy, Puncak Alam, UiTM for their assistance with this project.

\section{References}

Barrow, F., Heyman, I., Scott, S., \& Krebs, G. (2014). "Rituals or rivalry ?" The phenomenology and treatment of sibling speci fi c obsessions in paediatric obsessive-compulsive disorder. Journal of Obsessive-Compulsive and Related Disorders, 3(3), 209-214.

Blake, J. (1981). Family size and the quality of children. Demography, 18(4), 421-442. doi:10.2307/2060941

Chang, Y.-M., \& Luo, Z. (2015). Endogenous division rules as a family constitution: strategic altruistic transfers and sibling competition. Journal of Population Economics, 28(1), 173-194. doi:10.1007/s00148-013-0501-9

DeKeseredy, W. S., \& Ellis, D. (1997). Sibling Violence: A Review of Canadian Sociological Research and Suggestions for Further Empirical Work. Humanity \& Society, 21(4), 397-411. doi:10.1177/016059769702100405

Donovich, R., Puschmann, P., \& Matthijs, K. (2014). Rivalry, solidarity and longevity among siblings: A life course approach to the impact of sibship composition and birther order on later life mortality risks. Journal of Demographic Research, 31(UNSP 38), 1167-1198.

Eriksen, S., \& Jensen, V. (2009). A Push or a Punch: Distinguishing the Severity of Sibling Violence. Journal of Interpersonal Violence, 24(1), 183-208. doi:10.1177/0886260508316298

Fawcett, J. T., Arnold, F., Bulatao, R. A., Buripakdi, C., Chung, B. J., Iritani, T., . . Wu, T.-S. (1974). The value of children in Asia and the United States: comparative perspectives.

Feinberg, M. E., Sakuma, K. L., Hostetler, M., \& McHale, S. M. (2013). Enhancing sibling relationships to prevent adolescent problem behaviors: Theory, design and feasibility of siblings are special. Eval Program Planning, 36(1), 97-106.

George, M. W. (2008). The elements of library research: What every student needs to know. Retrieved from http://press.princeton.edu/chapters/s8711.html

Hoffman, K. L., \& Edwards, J. N. (2005). An integrated theoretical model of sibling violence and abuse. Journal of Family Violence, 19(3), 185200.

Hoffman, K. L., Kiecolt, K. J., \& Edwards, J. N. (2005). Physical Violence Between Siblings A Theoretical and Empirical Analysis. Journal of Family Issues, 26(8), 1103-1130. doi:10.1177/0192513x05277809

Jauhari, I., \& SH, M. (2014). A Comparison of Child Protection Law between Indonesia and Malaysia. Journal of Law, Policy and Globalization, 27.

Kerrane, B., Bettany, S. M., \& Kerrane, K. (2015). Siblings as socialization agents. European Journal of Marketing, , 49(5/6 ), 713 - 735.

Khan, R., \& Cooke, D. J. (2013). Measurement of Sibling Violence: A Two-Factor Model of Severity. Criminal Justice and Behavior, 40(1), $26-39$. doi:10.1177/0093854812463349

Kiong, T. C. (2005). Feuds and Legacies: Conflict and Inheritance in Chinese Family Businesses. International Sociology, 20(1), 45-70. doi:10.1177/0268580905049909

Kretschmer, T., \& Pike, A. (2010). Associations Between Adolescent Siblings' Relationship Quality and Similarity and Differences in Values. Journal of Family Psychology, 24(4), 411-418. doi:10.1037/a0020060

Lord, W. D., Boudreaux, M. C., Jarvis, J. P., Waldvogel, J., \& Weeks, H. (2002). Comparative Patterns in Life Course Victimization: Competition, Social Rivalry, and Predatory Tactics in Child Homicide in the United States. Homicide Studies, 6(4), 325-347. doi:10.1177/108876702237343 
Lukman, Z. (2009). Childhood abuse among children involved in prostitution in Malaysia. The Social Sciences, 4(6), 567-572.

Meyers, A. (2014). A call to child welfare: Protect children from sibling abuse. Qualitative Social Work, 13(5), 654-670. doi:10.1177/1473325014527332

$\mathrm{Ng}$, C. (2014, November 26). Domestic violence victims in Malaysia speak out to raise awareness. Astro Awani. Retrieved from http://english.astroawani.com/malaysia-news/domestic-violence-victims-malaysia-speak-out-raise-awareness-49155

Oshima, H. T. (1962). The international comparison of size distribution of family incomes with special reference to Asia. The Review of Economics and Statistics, 439-445.

Rapoza, K. A., Cook, K., Zaveri, T., \& Malley-Morrison, K. (2010). Ethnic Perspectives on Sibling Abuse in the United States. Journal of Family Issues, 31(6), 808-829. doi:10.1177/0192513×09359158

Rinfret-Raynor, M., \& Dube, M. (2000). Understanding Family Violence: Treating and Preventing Partner, Child, Sibling, and Elder Abuse. Canadian Journal of Criminology, 42(4), 515-515.

Shuib, R., Endut, N., Ali, S. H., Osman, I., Abdullah, S., Oon, S. W., .. Shahrudin, S. S. H. (2013). Domestic Violence and Women's Well-being in Malaysia: Issues and Challenges Conducting a National Study Using the WHO Multi-country Questionnaire on Women's Health and Domestic Violence Against Women. Procedia-Social and Behavioral Sciences, 91, 475-488.

Smith, A. L., Romski, M., \& Sevcik, R. A. (2013). Examining the Role of Communication on Sibling Relationship Quality and Interaction for Sibling Pairs With and Without a Developmental Disability. American Journal on Intellectual and Developmental Disabilities, 118(5), 394-409. doi:10.1044/ 0161-1461(2008/003)

Tan, M. K. S., Saini, M. S., Lee, V. Y., Wahab, S., Lai, F. C., ljam, M., . . Nor, N. K. (2014). Child Protection Issues: Incest-the Malaysian Scenario. Adolescent Psychiatry, 4(4), 225-232.

Tibbetts, G. (2014). War and peace: Attachment, conflict, and collaboration in adult sibling relationships. (MR87319 M.A.), Trent University (Canada), Ann Arbor. Retrieved from http://search.proquest.com.ezaccess.library.uitm.edu.my/docview/1462866632?accountid=42518 ProQuest Dissertations \& Theses Global database.

Tucker, C. J., \& Finkelhor, D. (2015). The State of Interventions for Sibling Conflict and Aggression: A Systematic Review. Trauma, Violence, \& Abuse. doi:10.1177/1524838015622438

van Beekum, S. (2009). Siblings, Aggression, and Sexuality: Adding the Lateral. Transactional Analysis Journal, 39(2), $129-135$. doi:10.1177/036215370903900206

Vivona, J. M. (2007). Sibling Differentiation, Identity Development, and the Lateral Dimension of Psychic Life. Journal of the American Psychoanalytic Association, 55(4), 1191-1215. doi:10.1177/000306510705500405

Wallace, A. D. (2015). Family and friendship William Wordsworth in Context (pp. 224-231).

Weiss, M. L. (2010). Malaysia-Indonesia bilateral relations: Sibling rivals in a fraught family. International relations in Southeast Asia: Between bilateralism and multilateralism, 171-198.

Whiteman, S. D., McHale, S. M., \& Soli, A. (2011). Theoretical Perspectives on Sibling Relationships. Journal of Family Theory \& Review, 3(2), 124-139. doi:10.1111/j.1756-2589.2011.00087.x

Yucel, D., \& Yuan, A. V. (2015). Do Siblings Matter? The Effect of Siblings on Socio-Emotional Development and Educational Aspirations among Early Adolescents. Child Indicators Research, 8(3), 671-697. doi:10.1007/s12187-014-9268-0 